\title{
Alagille syndrome: pathogenesis, diagnosis and management
}

\begin{abstract}
Alagille syndrome (ALGS), also known as arteriohepatic dysplasia, is a multisystem disorder due to defects in components of the Notch signalling pathway, most commonly due to mutation in JAG1 (ALGS type 1), but in a small proportion of cases mutation in NOTCH2 (ALGS type 2). The main clinical and pathological features are chronic cholestasis due to paucity of intrahepatic bile ducts, peripheral pulmonary artery stenosis, minor vertebral segmentation anomalies, characteristic facies, posterior embryotoxon/anterior segment abnormalities, pigmentary retinopathy, and dysplastic kidneys. It follows autosomal dominant inheritance, but reduced penetrance and variable expression are common in this disorder, and somatic/germline mosaicism may also be relatively frequent. This review discusses the clinical features of ALGS, including long-term complications, the clinical and molecular diagnosis, and management.
\end{abstract}

In brief

(1) Alagille syndrome (ALGS) is a complex autosomal dominant disorder due to defects in the Notch signalling pathway.

(2) The main body systems involved are the liver, heart, skeleton, face and eyes, but penetrance is variable, both within and between families.

(3) The main clinical features and malformations are chronic cholestasis due to paucity of intrahepatic bile ducts, congenital heart disease primarily affecting the pulmonary outflow tract and vasculature, butterfly vertebrae, characteristic facies with a broad forehead, posterior embryotoxon and/or anterior segment abnormalities of the eyes, and pigmentary retinopathy. Additional features are intracranial bleeding and dysplastic kidneys.
(4) The diagnosis is essentially clinical, dominated by the consequences of bile duct paucity - chronic cholestasis - and congenital heart disease.

(5) Almost $90 \%$ of cases are due to mutations in JAG1 (20p12), an additional $5-7 \%$ are due to deletions incorporating JAG1, and about $1 \%$ is due to mutations in NOTCH2 (1p13). ALGS may be referred to as type 1 (JAG1-associated) or type 2 (NOTCH2-associated).

(6) Genetic counselling for autosomal dominant inheritance must take account of variable expression, reduced penetrance and the possibility of germline mosaicism.

(7) Therapy is focused on the consequences of liver disease, as well as the surgical and medical treatment of congenital heart defects.

(8) The natural history and morbidity is related to the involvement, or otherwise, of various organ systems, especially the liver and heart.

\section{INTRODUCTION}

Alagille syndrome (ALGS; OMIM 118450) is a multisystem autosomal dominant disorder due to defects in the Notch signalling pathway, and can affect the liver, heart, skeleton, eyes, kidneys, and central nervous system, and there may be characteristic facial features. It is sometimes known as Alagille-Watson syndrome, as well as arteriohepatic dysplasia. Cases were first reported by Alagille et al in 1969, ${ }^{1}$ subsequently by Watson and Miller in $1973,{ }^{2}$ and again by Alagille

Peter D Turnpenny ${ }^{*, 1}$ and Sian Ellard ${ }^{2}$

${ }^{1}$ Department of Clinical Genetics, Royal Devon and Exeter Hospital, Exeter, UK; ${ }^{2}$ Molecular Genetics Laboratory, Royal Devon and Exeter Hospital, Exeter, UK

European Journal of Human Genetics (2012) 20, 251-257; doi:10.1038/ejhg.2011.181; published online 21 September 2011

Keywords: Alagille syndrome; arteriohepatic dysplasia; JAG1 gene; NOTCH2 gene; 20p12 deletion

*Correspondence: Dr PD Turnpenny, Department of Clinical Genetics, Royal Devon and Exeter Hospital, Gladstone Road, Exeter EX2 8AB, UK. Tel: +44 (0) 1392 405726; Fax: +44 (0) 1392 405739; E-mail: peter.turnpenny@rdeft.nhs.uk

Received 8 November 2010; revised 21 April 2011; accepted 29 April 2011; published online 21 September 2011 et al in $1975,{ }^{3}$ leading to the establishment of diagnostic criteria. The prevalence is reported to be $1: 70000$, based on the presence of neonatal liver disease, ${ }^{4}$ but this is almost certainly a significant underestimate, because it does not take into account the variability and reduced penetrance of the condition, which became clear through family studies and the advent of genetic testing. The majority of cases ( $\sim 97 \%$ ) are caused by haploinsufficiency of the JAG1 gene $\mathrm{e}^{5,6}$ on 20p11.2-20p12 (encoding JAGGED1), either due to mutations (the large majority) or deletions at the locus. A small percentage $(<1 \%)$ are caused by mutations in $\mathrm{NOTCH} 2,{ }^{7}$ in which group renal malformations may be more common. New mutations occur commonly $(\sim 60 \%)$, and the rate of germline mosaicism may also be relatively high. Both genes are components of the Notch signalling pathway.

\section{CLINICAL OVERVIEW}

Following the early delineation of ALGS cases were essentially ascertained through neonatal liver disease with conjugated hyperbilirubinaemia; indeed, the condition was more or less defined by this early presentation. In due course, the so-called 'Classic Criteria' (Table 1), based on the five main systems involved, were established. ${ }^{8}$ These are: cholestasis due to bile duct paucity, congenital heart disease (most commonly peripheral pulmonary artery stenosis), the face (mild, but 
Table 1 Classic Criteria, based on five body systems, for a diagnosis of Alagille syndrome

\begin{tabular}{ll}
\hline System/problem & Description \\
\hline Liver/cholestasis & $\begin{array}{l}\text { Usually presenting as jaundice with conjugated hyperbiliru- } \\
\text { binaemia in the neonatal period, often with pale stools }\end{array}$ \\
Dysmorphic facies & $\begin{array}{l}\text { Broad forehead, deep-set eyes, sometimes with upslanting } \\
\text { palpebral fissures, prominent ears, straight nose with } \\
\text { bulbous tip, and pointed chin giving the face a somewhat } \\
\text { triangular appearance } \\
\text { Most frequently peripheral pulmonary artery stenosis, but } \\
\text { disease }\end{array}$ \\
also pulmonary atresia, atrial septal defect (ASD), ventricular \\
septal defect (VSD), and Tetralogy of Fallot (TOF) \\
vertebral anomalies
\end{tabular}

recognisable dysmorphic features), the skeleton (abnormal vertebral segmentation, most commonly in the form of butterfly vertebrae), and the eye (anterior chamber defects, most commonly posterior embryotoxon). It was held that a diagnosis in a proband was sustainable if bile duct paucity was accompanied by three of the five main criteria. However, before the molecular genetic testing, variable expression was determined through segregation analysis, ${ }^{9}$ and it was suggested that the presence of only one feature was sufficient to make the diagnosis in the extended family.

A wide variety of clinical features and manifestations are now recognised in ALGS.

\section{Liver disease}

Chronic cholestasis occurs in a very high proportion $(\sim 95 \%)$ of cases, ${ }^{10}$ and most commonly, presents in the neonatal period or first 3 months of life, with jaundice due to conjugated hyperbilirubinaemia. Serum bile acids and liver function tests are raised, pruritus and growth failure may occur, and xanthomas may be present. A liver biopsy, no longer mandatory if cholestasis is present, typically shows paucity of the intrahepatic bile ducts, though in the newborn ductal proliferation may occasionally be seen, usually with portal inflammation, which may lead to a misdiagnosis of biliary atresia. This is important, because biliary atresia patients may undergo the Kasai procedure, which is not beneficial in ALGS. ${ }^{11}$ Bile duct paucity appears to be progressive, and may be more common in late infancy and early childhood compared with early infancy. Where serial liver biopsies have been performed, bile duct paucity was present in $60 \%$ of infants less than 6 months old, and in 95\% after 6 months. Progressive liver disease, eventually causing cirrhosis and failure, and requiring liver transplantation, occurs in approximately $15 \%$ of cases. ${ }^{10}$ Although there is no reliable way of predicting which infants are at high risk, those who subsequently manifest progressive liver disease have been shown to have chronically elevated total bilirubin, conjugated bilirubin, and cholesterol. ${ }^{12}$ A small proportion of patients have no manifestations of liver disease. ${ }^{13,14}$

\section{Heart disease}

There is evidence of cardiovascular anomalies in more than $90 \%$ of ALGS subjects. ${ }^{15}$ Involvement of the pulmonary outflow tract is the most common type of congenital heart disease, with some form of

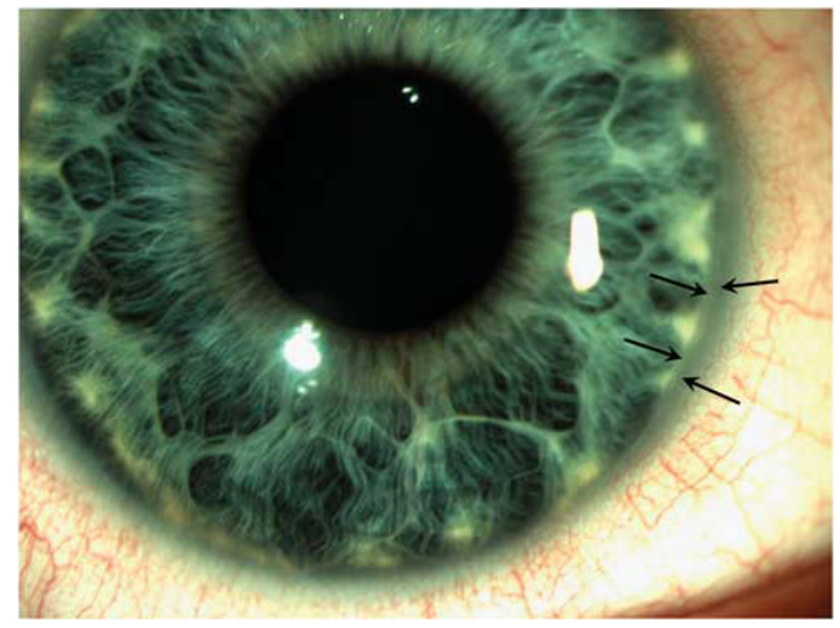

Figure 1 Posterior embryotoxon (arrowed). Courtesy of Mr Anthony Quinn.

peripheral pulmonary stenosis (PPS) affecting at least two-thirds of cases. ${ }^{10,15}$ Tetralogy of Fallot (TOF) is the most common complex structural anomaly, occurring in up to $16 \%$ of cases. ${ }^{10,15}$ Other malformations include ventricular septal defect, atrial septal defect, aortic stenosis, and coarctation of the aorta, and hypoplastic left heart syndrome has been reported in one patient with a $20 \mathrm{p} 12$ deletion. ${ }^{16}$ Congenital heart disease may be the sole manifestation of ALGS, if the condition is defined by a positive genotype. JAG1 mutations have been found in families with several generations of PPS but no liver disease, and in screening cell lines of patients with apparently isolated TOF, 7\% were found to have mutations in JAG1. ${ }^{13}$ The presence of complex congenital heart disease appears to be the most significant indicator of early mortality, probably because it is usually associated with PPS, whereas hepatic complications account for a significant proportion of later deaths.

\section{Ophthalmic features}

Posterior embryotoxon, the most common ophthalmic feature of ALGS, has been reported in up to $90 \%$ of patients. ${ }^{17}$ This is prominence of the centrally positioned Schwalbe's ring (or line) at the point where the corneal endothelium and the uveal trabecular meshwork join (Figure 1). However, this also occurs in up to $15 \%$ of the normal population, as well as nearly $70 \%$ of patients with deletion 22q11 syndrome. ${ }^{18} \mathrm{~A}$ wide variety of ophthalmic abnormalities may be seen in ALGS affecting the cornea, iris, retina, and optic disk. Axenfeld anomaly, a prominent Schwalbe's ring with attached iris strands, is seen in $13 \%$ of ALGS patients, an unusual mosaic pattern of iris stromal hypoplasia, ${ }^{19}$ microcornea, keratoconus, congenital macular dystrophy, shallow anterior chamber, exotropia, band keratopathy, and cataracts. Diffuse hypopigmentation of the retinal fundus may occur in up to $57 \%$ of patients, but speckling of the retinal pigment epithelium in 33\%, and optic disc abnormalities in $76 \%$. Nischal et $a l^{20}$ found evidence of optic disk drusen in at least one eye in $95 \%$ of patients, and bilateral in $80 \%$ (but not in liver disease patients without ALGS). Generally speaking, visual prognosis is good.

\section{Skeletal anomalies}

A characteristic form of segmentation anomaly known as 'butterfly' vertebrae (Figure 2) may occur in at least $80 \%$ of cases. ${ }^{21}$ This consists of a sagittal cleft in one or more thoracic vertebrae, visible 


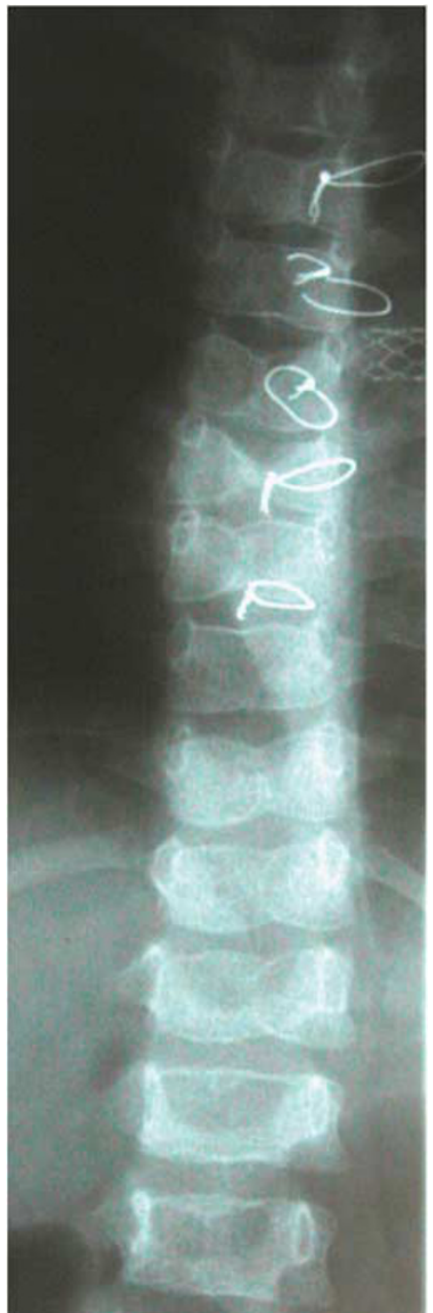

Figure 2 Butterfly vertebrae seen in the thoracic and upper lumbar regions. The child had undergone cardiac surgery, hence the presence of visible wires.

on antero-posterior radiograph, and is due to failure of fusion of the anterior vertebral arches. Vertebral segmentation anomalies occur in a wide range of disorders ${ }^{22}$ but, with the exception of deletion $22 \mathrm{q} 11$ syndrome (again), the relatively symmetrical 'butterfly' appearance is unusual. These are of no structural significance, and may not be noticed in a sick infant for whom all the medical care is focused on treating congenital heart disease, for example. Other axial skeletal features include narrowing of the interpedicular distance in the lumbar spine, pointed anterior process of $\mathrm{C} 1$, spina bifida occulta and fusion of adjacent vertebrae, hemivertebrae, and absence of the 12th rib. ${ }^{23,24}$ Craniosynostosis has been reported, ${ }^{25}$ as well as radioulnar synostosis, ${ }^{26}$ and the digits may show shortening of the distal phalanges with fingers that have a fusiform appearance (Figure 3). It is not unusual for ALGS patients to develop metabolic bone disease with osteoporosis and fractures, most likely a consequence of multi-organ involvement, and a sub-optimal nutritional state. A recent retrospective survey of ALGS families highlighted fractures in $28 \%$ of 42 subjects with a mean age of 5 years, affecting the lower limb long bones in $70 \%{ }^{27}$

\section{The face}

It is well reported that children with ALGS have mild but recognisable dysmorphic features including a prominent forehead, deep-set eyes

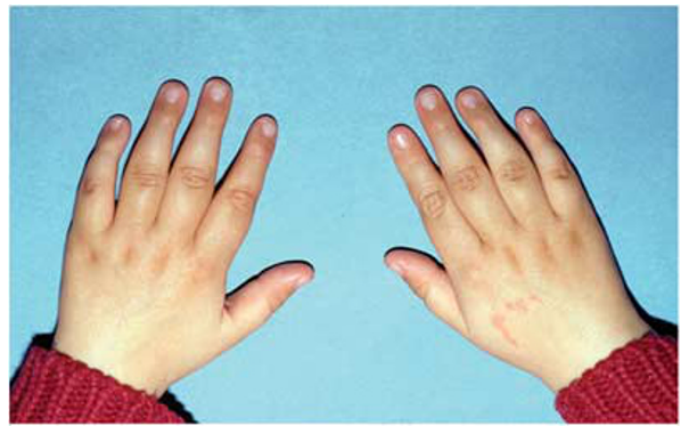

Figure 3 The hands of the child shown in Figure 4a. The digits are generally fusiform in shape and the terminal phalanges somewhat hypoplastic. Courtesy of Dr Peter Lunt.
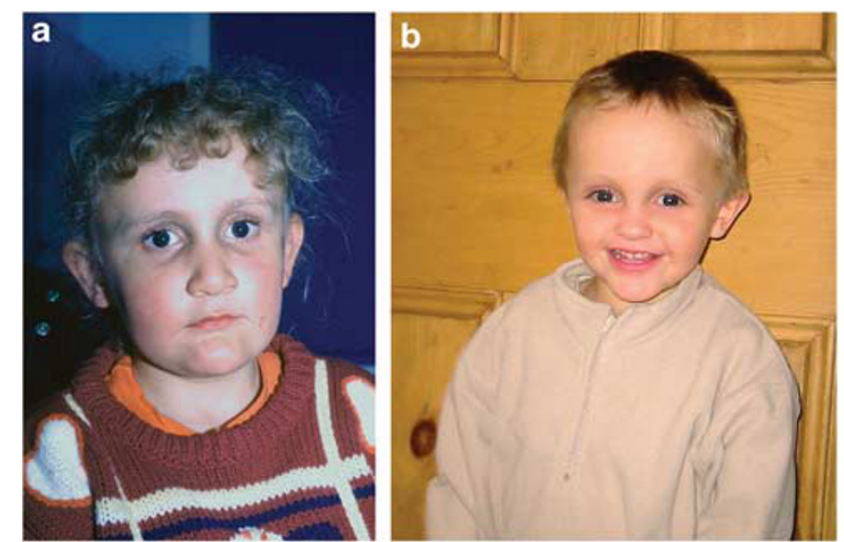

Figure 4 Two children, (a) and (b) with AGS. Both manifest deep-set eyes, a broad nasal root, and prominent chin. The palpebral fissures are not upslanting, and hypertelorism does not appear to be present. Courtesy of Drs Peter Lunt, Alison Male, and Simon Holden.

with moderate hypertelorism, upslanting palpebral fissures, depressed nasal bridge, straight nose with a bulbous tip, large ears, prominent mandible, and pointed chin. ${ }^{28}$ In some children, the shape of the face is strikingly triangular. The prominence of the forehead is said to be less noticeable by adult life, whereas protrusion of the mandible and chin is more obvious. In this review, we put forward the opinion that the facial phenotype differs according to whether the eyes are deep-set or not. Figure 4 shows two young people with fairly deep-set eyes, but the palpebral fissures are not obviously upslanting, and there is no definite impression of hypertelorism. Figure 5, however, shows two children and an older person with obvious upslanting and narrow palpebral fissures, their eyes are not deep-set, and they appear to have hypertelorism. We argue that the overall gestalt differs on the basis of the eyes, but there are overlapping features, and both faces are recognisable.

\section{Vascular events}

Vascular accidents have been reported to occur in up to $15 \%$ of cases, ${ }^{10}$ and were a cause of death in $34 \%$ in one series. ${ }^{29}$ Intracranial bleeding may occur as a consequence of relatively minor head trauma. Studies have identified anomalies of the basilar, carotid, and middle cerebral arteries, ${ }^{29,30}$ and renovascular anomalies, middle aortic syndrome, and Moyamoya syndrome have all been reported. The vascular aspects of ALGS are considered further in the next section. 

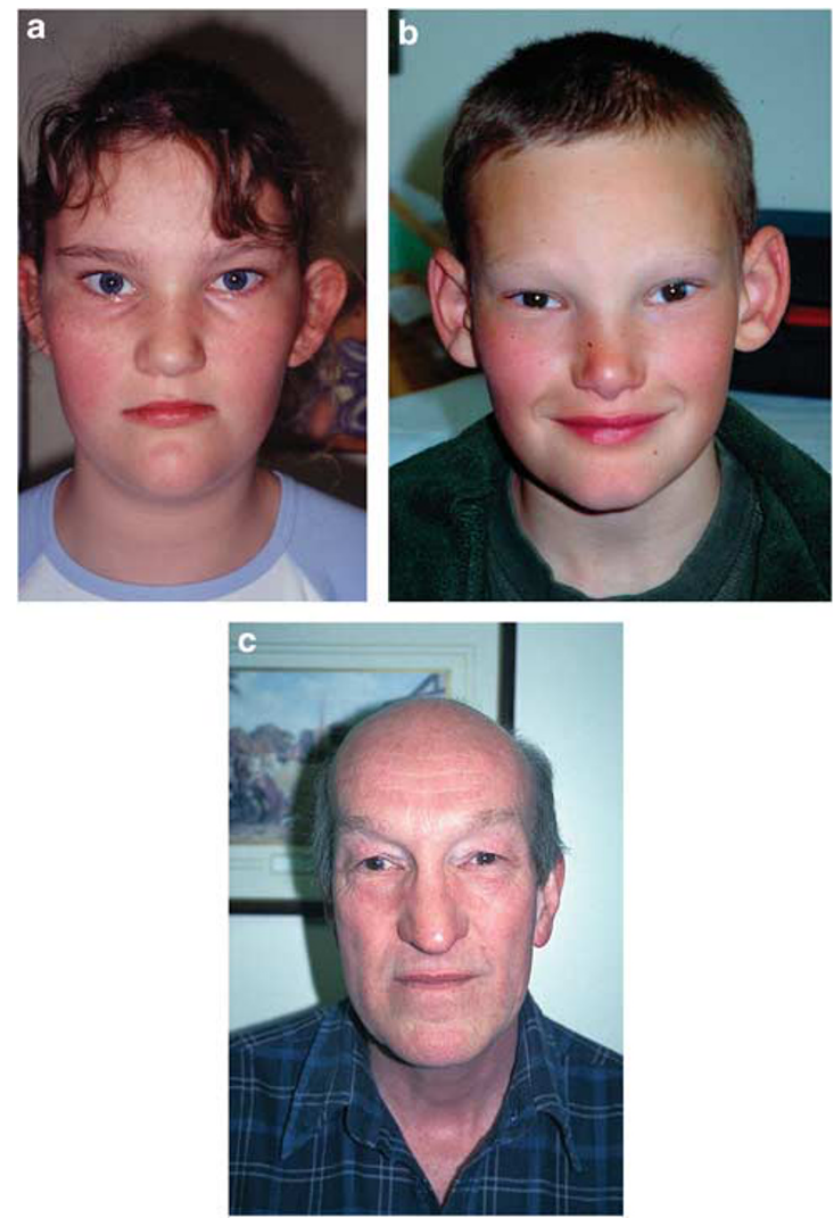

Figure 5 Two children, (a) and (b), and an adult, (c), with ALGS. None of the three have deep-set eyes, but their palpebral fissures are obviously upslanting and narrow. They possibly have a degree of hypertelorism. Courtesy of Drs Daniela Pilz, Carole Brewer, and Mr Alan Hardie. (b) Is reproduced by kind permission of Elsevier; the image is published as Figure $6.5 \mathrm{~A}$ in Emery's Elements of Medical Genetics, 14th edition, Turnpenny and Ellard.

\section{Renal anomalies}

Structural problems such as small, echogenic kidneys, cysts, and ureteropelvic obstruction all occur in ALGS. ${ }^{10}$ There may also be a functional abnormality, particularly renal tubular acidosis, which may occur in up to $74 \%$ of cases. ${ }^{10}$ The first reports of NOTCH2-associated $\mathrm{ALGS}^{7}$ suggested that renal abnormalities may occur more frequently in ALGS type 2 compared with type 1, but further data is required.

\section{Growth}

Significant growth retardation occurs in a high proportion of subjects. ${ }^{10,31}$ Malabsorption, leading to failure to thrive, and malnutrition is likely to be the main cause, but there may be limitations to growth potential regardless of nutritional status. ${ }^{32}$ Hypothyroidism has been described in some ALGS patients, and delayed puberty can occur. Growth hormone insensitivity has also been reported in children, ${ }^{33}$ and there are, therefore, a number of possible reasons to explain short stature in ALGS.

\section{The pancreas}

Pancreatic insufficiency appears to occur in a proportion of patients, perhaps up to $40 \%,{ }^{10,34}$ but assessment is complicated by the presence of bile duct paucity, which has traditionally been considered to be the cause of steatorrhea. However, oral pancreatic supplementation has been beneficial, and some patients have developed insulin-dependent diabetes mellitus.

\section{Learning difficulties}

Early studies highlighted a relatively high frequency of mental retardation, ${ }^{8}$ but this may have represented ascertainment bias. With aggressive treatment, learning difficulties may be no more common than the general population, though there appears to be an increased frequency of motor delay, affecting some $16 \%$. Learning difficulties are more likely in those cases due to relatively large cytogenetic deletions encompassing chromosome 20p12.

\section{PATHOGENESIS}

Paucity of bile ducts was essential to the diagnosis of ALGS under the 'Classic Criteria' (Table 1), and is still a frequent, key feature (80-90\%) in large series of patients. ${ }^{10,35}$ A progression to paucity appears to develop through infancy, accompanied by deterioration in liver function. However, such progression does not always occur. It is no longer considered likely that there is a failure of development of interlobular bile ducts, and the factors leading to a decreased number of ducts are poorly understood. The full role of the JAG1 protein in the development of new ducts in infancy is not yet clear. A reduction in the number of portal tracts has been reported, ${ }^{36}$ and ductular proliferation has been seen in a small number of infants with ALGS. The reasons for these differences are not clear.

The widely variable phenotype in ALGS raises questions about the primary role of the genotype in giving rise to features, or whether at least some of the effects are secondary to medical complications. Debate has taken place about the possibility that the distinctive facies is not a primary malformation, but secondary to the consequences of cholestasis. ${ }^{37}$ However, a panel of dysmorphologists was readily able to distinguish patients with ALGS from those with other forms of cholestasis, ${ }^{38}$ thus strongly suggesting a primary effect of the genotype. A more substantial consideration relates to the possibility that ALGS is primarily a vasculopathy. The vascular anomalies of ALGS are widespread, ${ }^{29}$ prompting the notion that at least some of the effects are traceable to abnormalities of angiogenesis and the vascular system. There is evidence that the formation of mature tubular bile ducts follows on from development of the intrahepatic arterial network. ${ }^{39}$ However, more fundamentally, the genes implicated in ALGS, JAG1 and $\mathrm{NOTCH} 2$, are components of the Notch signalling pathway, which has a major role in angiogenesis.

\section{JAG1 gene}

JAG1 is implicated in the large majority of cases of ALGS, and the gene is not implicated in any other phenotype. Mutations were identified in ALGS patients by two groups. ${ }^{5,6}$ It consists of 26 exons, and encodes the JAGGED1 cell surface protein that functions as a ligand for the Notch receptors, Notch 1, 2, 3, and 4. These receptors are transmembrane proteins, and interaction with their ligands triggers a cascade of intracellular downstream effects that result in transcription of genes that help determine cell fate and differentiation, for example segmentation boundaries in the presomitic mesoderm. Phenotypes associated with specific genes include spondylocostal dysostosis (DLL3, MESP2, LFNG, and HES7), and CADASIL (NOTCH3). The latter is an adultonset condition characterised by an arteriopathy, which gives rise to migraine and strokes. The JAG1 homozygous knockout mouse demonstrates early lethality from vascular defects, ${ }^{40}$ as do some other mice that are homozygously knocked out for Notch pathway 
genes, for example Dll1. It is therefore reasonable to postulate a vasculogenesis role for JAG1 in humans, though this does not necessarily explain the features seen in ALGS patients. Interestingly, the heterozygous mouse knockout for Jag1 manifests ocular abnormalities alone, but the mouse that is compound heterozygous for Jag1 and Notch 2 mutations resembles the phenotype of ALGS closely. ${ }^{41}$

In patients with a convincing clinical diagnosis of ALGS, mutations in JAG1, or deletions encompassing the gene on 20p12, can be detected in up to $95 \%$ of cases. More than 400 JAG1 mutations have been identified thus far, of which $\sim 70 \%$ are protein-truncating. There are no particular hotspots, and any part of the entire coding region may be involved. ${ }^{42,43}$ Gene deletions are found in up to $7 \%$ of cases, and there appears to be a critical region of $5.4 \mathrm{Mb}$, whereby the phenotype does not differ significantly from mutation cases. However, larger deletions are likely to be associated with additional problems such as learning difficulties. ${ }^{44}$ The occasional finding of a cytogenetically visible deletion or rearrangement involving 20p12 was significant in allocating the ALGS locus to this region, ${ }^{9,45}$ and the similarity of the phenotype between deletion and mutation cases suggests that haploinsufficiency is the mutational mechanism. Approximately $60 \%$ of mutations are de novo, and germline mosaicism may occur at a frequency up to $8 \%,{ }^{46}$ which must not be overlooked in genetic counselling, where appropriate.

There is very little evidence for genotype-phenotype correlation for JAG1 and ALGS. However, the G274D mutation was found to be segregating with isolated structural heart disease in one family, where all cases had full or partial forms of $\mathrm{TOF}^{47}$

\section{NOTCH2 gene}

Like JAG1, NOTCH2 is a large gene that comprises 34 exons and encodes the NOTCH2 transmembrane protein. The fact that mice compound heterozygotes for Jag1 and Notch2 mutations have a phenotype that is close to ALGS in humans led to sequencing of the $\mathrm{NOTCH} 2$ gene in cases of ALGS that were negative for mutations in JAG1. Thus far, only two families with $\mathrm{NOTCH} 2$ mutations have been reported. ${ }^{7}$ The affected individuals (a total of five in the two families) had typical features of ALGS, but renal problems were moderately severe. There is insufficient data at present to look into genotypephenotype correlations.

A small proportion of patients fulfilling the classic criteria for ALGS do not appear to have either a mutation or deletion involving JAG1 or NOTCH2, making further genetic heterogeneity likely. An 'Alagille-like' syndrome, following autosomal recessive inheritance, but not linked either to JAG1 or NOTCH2, has been reported in a native Canadian family. ${ }^{48}$ Affected individuals had bile duct paucity, cholestasis, and pulmonary stenosis.

\section{DIAGNOSIS}

ALGS is now defined by its genotype as well as its phenotype, but significant clinical challenges remain. For example, paucity of bile ducts, a histological diagnosis from liver biopsy, occurs in a diverse group of conditions, which, apart from ALGS, include Down syndrome, cystic fibrosis, congenital infections, alpha-1-antitrypsin deficiency, and Zellweger and Ivemark syndromes. For none of these disorders, including ALGS, is bile duct paucity a constant feature and, as previously discussed, the situation changes over time. The presence of cholestasis is now considered sufficient, without the need for routine liver biopsy. Similarly, pulmonary stenosis and related forms of congenital heart disease occur in isolation and as part of a wide range of syndromes; for example the disorders of the RAS-MAPK pathway and deletion 22q11 syndrome. However, PPS is more specific and should always prompt consideration of ALGS - if the patient does not have Williams syndrome.

Liver disease and PPS are the most prevalent features seen in patients with ALGS, but the condition is extremely variable. Kamath et al $^{14}$ evaluated 53 mutation-positive relatives of 34 probands with ALGS. Only 11 (21\%) had clinical features that would have unequivocally led to a diagnosis of ALGS; 17 (32\%) had mild features of ALGS after targeted investigation; 25 (47\%) did not meet clinical criteria for ALGS, and 2 of these patients had no features at all. In an audit of 241 cases referred for ALGS testing at the Exeter Molecular Genetics Laboratory (UK), JAG1 mutations were identified in 59/135 (44\%) probands and $24 / 106(23 \%)$ of their relatives. ${ }^{49}$ In probands with three features of ALGS, mutations were found in $54 \%$ of cases, whereas mutations were found in $34 \%$ of those with only one or two clinical features of ALGS. This audit was dependent on the accuracy of clinical data supplied by referring clinicians, but overall, the implications are as follows:

(1) In patients with three features of ALGS, the JAG1 mutation pick-up rate was not as high as expected;

(2) The mutation-positive pick-up rate was surprisingly high in those with fewer features of ALGS;

(3) Clinicians should have a high index of clinical suspicion for ALGS and a low threshold for testing.

The clinical conundrum surrounding ALGS, combined with the advent of molecular diagnostic testing, led Kamath et al ${ }^{50}$ to offer revised diagnostic criteria for ALGS. Here we offer a practical diagnostic flow chart, depicted in Figure 6. Although Warthen et a $l^{51}$ achieved a

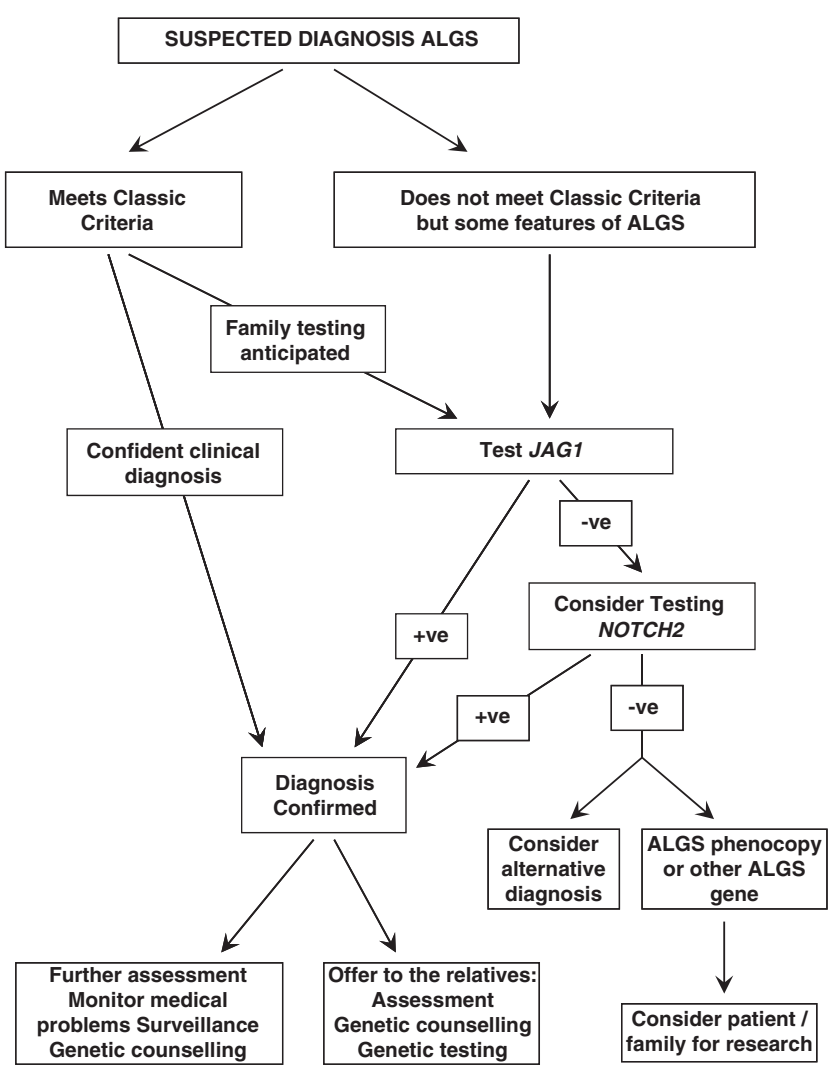

Figure 6 Flow diagram of genetic investigations and management for suspected ALGS patients. 
JAG1 mutation detection rate of $94 \%$ in a large cohort of clinically well-defined patients, in routine practice, the pick-up rate will be significantly lower. Negative JAG1 findings can be expected in up to $\sim 40 \%$ of patients suspected to have ALGS, ${ }^{52-56}$ but the pick-up rate depends very much on the strictness of the clinical criteria applied to the testing threshold in probands.

\section{MANAGEMENT}

For the patient diagnosed with ALGS, the important evaluations to undertake, if not already performed in pursuit of a diagnosis, include:

(1) Assessment by a paediatrician/physician/gastroenterologist, including liver function tests (the conjugated hyperbilirubinaemia of ALGS is associated with high GGT levels), serum cholesterol and triglycerides, bile acids, clotting studies, liver ultrasound, scintiscan, and biopsy;

(2) Detailed cardiac assessment;

(3) AP spinal X-ray;

(4) Ophthalmic assessment;

(5) Renal ultrasound and renal function tests.

In addition, when the diagnosis is made in infancy or childhood, monitoring of growth, development, diet and nutritional status, renal tubular function, and pancreatic function should all be undertaken. This requires a multidisciplinary approach. Expert dietary input and supplementary feeding may be necessary.

In the child with significant liver disease, pruritus can be severe, but successfully treated with choloretic agents such as ursodeoxycholic acid and cholestyramine, rifampin, or naltrexone. Biliary diversion may be very helpful, and can be useful before liver transplantation. In certain cases, partial external biliary diversion has also proved successful. ${ }^{57}$ The success of liver transplantation itself is often related to coexisting cardiac and renal impairment, and these systems must be very carefully evaluated. ${ }^{58}$ The 5 -year survival following transplantation is $80 \%$, and results in improvement in liver function and growth in $90 \%$ of cases. ${ }^{59}$ For live donors from the biological relatives, genetic testing to rule out gene carrier status should be undertaken, in which the mutation is known. Contact sports should be avoided if splenomagaly is present, and alcohol consumption should not feature at any age if there is concern about liver function.

The management of cardiac and renal malformations or disease will follow the practice appropriate to the particular problems encountered, and similarly for vascular accidents. It is very unlikely that vertebral anomalies will require any intervention, and the same applies to most ophthalmic features seen in ALGS.

All efforts should be made to maximise growth potential, which is compromised in a significant proportion of cases. Careful attention to nutrition is therefore a key aspect of management, especially in the symptomatic child. This constitutes the single, most important reason for ongoing surveillance in the young person. The presence of vascular anomalies may be made worse by deteriorating liver function that affects coagulation, which also needs to be monitored. Screening for vascular anomalies, especially intracranial lesions, may not generate any benefit for the patient, and this question therefore needs to be dealt with cautiously and with discernment.

\section{CONCLUSION}

The diagnosis of ALGS should not be missed when the patient has features that meet the Classic Criteria, and investigation, surveillance, and family management can follow. However, the diagnosis can be very difficult in a family without an individual who fulfils the Classic
Criteria. ALGS is therefore a condition presenting challenges to clinical judgment, decisions about genetic testing, and counselling for the wider family. In general, a high index of clinical suspicion and a low threshold for genetic testing will help to ensure that most cases are diagnosed.

\section{CONFLICT OF INTEREST}

The authors declare no conflict of interest.

\section{ACKNOWLEDGEMENTS}

We are grateful to Drs Anthony Quinn, Peter Lunt, Alison Male, Simon Holden, Carole Brewer, Daniela Pilz, and Alan Hardie for allowing their patients to feature in this review, and the patients themselves.

1 Alagille D, Habib EC, Thomassin N: L'atresie des voies biliaires intrahepatiques avec voies biliaires extrahepatiques permeables chez l'enfant. Editions Medicales Flammarion, Paris: 1969 , pp 301-318.

2 Watson GH, Miller V: Arterio-hepatic dysplasia. Familial pulmonary arterial stenosis with neonatal liver diseases. Arch Dis Child 1973; 48: 459-466.

3 Alagille D, Odièvre M, Gautier M, Dommergues JP: Hepatic ductular hypoplasia associated with characteristic facies, vertebral malformations, retarded physical, mental, and sexual development, and cardiac murmur. J Pediatr 1975; 86: 63-71.

4 Danks DM, Campbell PE, Jack I, Rogers J, Smith AL: Studies of the aetiology of neonatal hepatitis and biliary atresia. Arch Dis Child 1977; 52: 360-367.

$5 \mathrm{Li}$ L, Krantz ID, Deng Y et al: Alagille syndrome is caused by mutations in human Jagged1, which encodes a ligand for Notch1. Nat Genet 1997; 16: 243-251.

6 Oda T, Elkahloun AG, Pike BL et al: Mutations in the human Jagged1 gene are responsible for Alagille syndrome. Nat Genet 1997; 16: 235-242.

7 McDaniell R, Warthen DM, Sanchez-Lara PA, Pai A, Krantz ID, Piccoli DA, Spinner NB: NOTCH2 mutations cause Alagille syndrome, a heterogeneous disorder of the Notch signaling pathway. Am J Hum Genet 2006; 79: 169-173.

8 Alagille D, Estrada A, Hadchouel M, Gautier M, Odièvre M, Dommergues JP: Syndromic paucity of interlobular bile ducts (Alagille syndrome or arteriohepatic dysplasia): review of 80 cases. J Pediat 1987; 110: 195-200.

9 Dhorne-Pollet S, Deleuze J-F, Hadchouel M, Bonaiti-Pellie C: Segregation analysis of Alagille syndrome. J Med Genet 1994; 31: 453-457.

10 Emerick KM, Rand EB, Goldmuntz E, Krantz ID, Spinner NB, Piccoli DA: Features of Alagille syndrome in 92 patients: frequency and relation to prognosis. Hepatology 1999; 29: 822-829.

11 Kaye AJ, Rand EB, Munoz PS, Spinner NB, Flake AW, Kamath BM: Effect of Kasai procedure on hepatic outcome in Alagille syndrome. J Pediatr Gastroenterol Nutr 2010; 51: 319-321.

12 Kamath BM, Munoz PS, Bab N, Baker A, Chen Z, Spinner NB, Piccoli DA: A longitudinal study to identify laboratory predictors of liver disease outcome in Alagille syndrome. J Pediatr Gastroenterol Nutr 2010; 50: 526-530.

13 Krantz ID, Smith R, Colliton RP et al: Jagged 1 mutations in patients ascertained with isolated congenital heart defects. Am J Med Genet 1999; 84: 56-60.

14 Kamath BM, Bason L, Piccoli DA, Krantz ID, Spinner NB: Consequences of JAG1 mutations. J Med Genet 2003; 40: 891-895.

15 McElhinney DB, Krantz ID, Bason L et al: Analysis of cardiovascular phenotype and genotype-phenotype correlation in individuals with a JAG1 mutation and/or Alagille syndrome. Circulation 2002; 106: 2567-2574.

16 Robert ML, Lopez T, Crolla J et al: Alagille syndrome with deletion 20p12.2-p12.3 and hypoplastic left heart. Clin Dysmorphol 2007; 16: 241-246.

17 Hingorani M, Nischal KK, Davies A et al: Ocular abnormalities in Alagille syndrome. Ophthalmology 1999; 106: 330-337.

18 McDonald-McGinn DM, Kirschner R, Goldmuntz E et al: The Philadelphia story: the 22q11.2 deletion: report on 250 patients. Genet Couns 1999; 10: 11-24.

19 Brodsky MC, Cunniff C: Ocular anomalies in the Alagille syndrome (arteriohepatic dysplasia). Ophthalmology 1993; 100: 1767-1774.

20 Nischal KK, Hingorani M, Bentley CR et al: Ocular ultrasound in Alagille syndrome: a new sign. Ophthalmology 1997; 104: 79-85.

21 Sanderson E, Newman V, Haigh SF, Baker A, Sidhu PS: Vertebral anomalies in children with Alagille syndrome: an analysis of 50 consecutive patients. Pediatr Radiol 2002; 32: 114-119.

22 Turnpenny PD, Alman B, Cornier AS et al: Abnormal vertebral segmentation and the Notch signaling pathway in man. (Review). Dev Dynamics 2007; 236: 1456-1474.

23 Greenwood RD, Rosenthal A, Crocker AC, Nadas AS: Syndrome of intrahepatic biliary dysgenesis and cardiovascular malformations. Pediatrics 1976; 58: 243-247.

24 Berrocal T, Gamo E, Navalón J et al: Syndrome of Alagille: radiological and sonographic findings. A review of 37 cases. Eur Radiol 1997; 7: 115-118.

25 Kamath BM, Stolle C, Bason L et al: Craniosynostosis in Alagille syndrome. Am J Med Genet 2002; 112: 176-180.

26 Ryan RS, Myckatyn SO, Reid GD, Munk P: Alagille syndrome: case report with bilateral radio-ulnar synostosis and a literature review. Skeletal Radiol 2003; 32: 489-491. 
27 Bales CB, Kamath BM, Munoz PS et al: Pathologic lower extremity fractures in children with Alagille syndrome. J Pediatr Gastroenterol Nutr 2010; 51: 66-70.

28 Krantz ID, Piccoli DA, Spinner NB: Alagille syndrome. J Med Genet 1997; 34: 152-157.

29 Kamath BM, Spinner NB, Emerick KM et al: Vascular anomalies in Alagille syndrome: a significant cause of morbidity and mortality. Circulation 2004; 109: 1354-1358.

30 Emerick KM, Krantz ID, Kamath BM et al: Intracranial vascular abnormalities in patients with Alagille syndrome. J Pediatr Gastroenterol Nutr 2005; 41: 99-107.

31 Arvay JL, Zemel BS, Gallagher PR et al: Body composition of children aged 1 to 12 years with biliary atresia or Alagille syndrome. J Pediatr Gastroenterol Nutr 2005; 40: $146-150$.

32 Olsen IE, Ittenbach RF, Rovner AJ et al: Deficits in size-adjusted bone mass in children with Alagille syndrome. J Pediatr Gastroenterol Nutr 2005; 40: 76-82.

33 Bucuvalas JC, Horn JA, Carlsson L, Balistreri WF, Chernausek SD: Growth hormone insensitivity associated with elevated circulating growth hormone-binding protein in children with Alagille syndrome and short stature. J Clin Endocr Metab 1993; 76: 1477-1482

34 Chong SK, Lindridge J, Moniz C, Mowat AP: Exocrine pancreatic insufficiency in syndromic paucity of interlobular bile ducts. J Pediatr Gastroenterol Nutr 1989; 9: 445-449.

35 Deprettere A, Portmann B, Mowat AP: Syndromic paucity of the intrahepatic bile ducts: diagnostic difficulty; severe morbidity throughout early childhood. J Pediatr Gastroenterol Nutr 1987; 6: 865-871.

36 Hashida Y, Yunis EJ: Syndromatic paucity of interlobular bile ducts: hepatic histopathology of the early and endstage liver. Pediatr Pathol 1988; 8: 1-15.

37 Sokol RJ, Heubi JE, Balistreri WF: Intrahepatic 'cholestasis facies': is it specific for Alagille syndrome? J Pediatr 1983; 103: 205-208.

38 Kamath BM, Loomes KM, Oakey RJ et al: Facial features in Alagille syndrome: Specific or Alagille syndrome? Am J Med Genet 2002; 112: 163-170.

39 Libbrecht L, Cassiman D, Desmet V, Roskams T: The correlation between portal myofibroblasts and development of intrahepatic bile ducts and arterial branches in human liver. Liver 2002; 22: 252-258.

40 XueY, Gao X, Lindsell CE et al: Embryonic lethality and vascular defects in mice lacking the Notch ligand Jagged1. Hum Mol Genet 1999; 8: 723-730.

41 McCright B, Lozier J, Gridley T: A mouse model of Alagille syndrome: Notch2 as a genetic modifier of Jag1 haploinsufficiency. Development 2002; 129: 1075-1082.

42 Spinner NB, Colliton RP, Crosnier C, Krantz ID, Hadchouel M, Meunier-Rotival M: Jagged 1 mutations in alagille syndrome. (Review). Hum Mutat 2001; 17: 18-33.
43 Röpke A, Kujat A, Gräber M, Giannakudis J, Hansmann I: Identification of 36 novel Jagged1 (JAG1) mutations in patients with Alagille syndrome. Hum Mutat 2003; 21: 100.

44 Kamath BM, Thiel BD, Gai X et al: SNP array mapping of chromosome 20p deletions: genotypes, phenotypes, and copy number variation. Hum Mutat 2009; 30: 371-378.

45 Byrne JL, Harrod MJ, Friedman JM: Howard-Peebles PN: Del(20p) with manifestations of arteriohepatic dysplasia. Am J Med Genet 1986; 24: 673-678.

46 Giannakudis J, Ropke A, Kujat A et al: Paternal mosaicism of JAG1 mutations in families with Alagille syndrome. Eur J Hum Genet 2001; 9: 209-216.

47 Eldadah ZA, Hamosh A, Biery NJ et al: Familial Tetralogy of Fallot caused by mutation in the jagged1 gene. Hum Mol Genet 2001; 10: 163-169.

48 Dyack S, Cameron M, Otley A, Greer W: An autosomal recessive form of Alagille-like syndrome that is not linked to JAG1. Genet Med 2007; 9: 544-550.

49 Guegan K, Stals K, Day M, Turnpenny P, Ellard S: JAG1 mutations are found in approximately one third of patients presenting with one or two clinical features of Alagille syndrome. Clin Genet 2011; e-pub ahead of print 13 July 2011, doi: 10.1111/ j.1399-0004.2011.01749.x.

50 Kamath BM, Spinner NB, Piccoli DA: Alagille syndrome; in: Suchy (ed): Liver Disease in Children. 3rd edn, New York: Cambridge University Press, 2007, pp 326-345.

51 Warthen DM, Moore EC, Kamath BM et al: Jagged1 (JAG1) mutations in Alagille syndrome: increasing the mutation detection rate. Hum Mutat 2006; 27: 436-443.

52 Krantz ID, Colliton RP, Genin A et al: Spectrum and frequency of jagged1 (JAG1) mutations in Alagille syndrome patients and their families. Am J Hum Genet 1998; 62: 1361-1369.

53 Pilia G, Uda M, Macis D et al: Jagged-1 mutation analysis in Italian Alagille syndrome patients. Hum Mutat 1999; 14: 394-400.

54 Colliton RP, Bason L, Lu FM, Piccoli DA, Krantz ID, Spinner NB: Mutation analysis of Jagged1 (JAG1) in Alagille syndrome patients. Hum Mutat 2001; 17: 151-152.

55 Heritage ML, MacMillan JC, Anderson GJ: DHPLC mutation analysis of Jagged1 (JAG1) reveals six novel mutations in Australian alagille syndrome patients. Hum Mutat 2002; 20: 481.

56 Jurkiewicz D, Popowska E, Gläser C, Hansmann I, Krajewska-Walasek M: Twelve novel JAG1 gene mutations in Polish Alagille syndrome patients. Hum Mutat 2005; 25: 321.

57 Mattei P, von Allmen D, Piccoli D, Rand E: Relief of intractable pruritus in Alagille syndrome by partial external biliary diversion. J Pediatr Surg 2006; 41: 104-107.

58 Kamath BM, Schwarz KB, Hadzić N: Alagille syndrome and liver transplantation. J Pediatr Gastroenterol Nutr 2010; 50: 11-15.

59 Kasahara M, Kiuchi T, Inomata Y et al: Living-related liver transplantation for Alagille syndrome. Transplantation 2003; 75: 2147-2150. 